\title{
The Cultivation of Cultural Engineers in University of Technology
}

\author{
Xiaofeng Jia \\ School of Foreign Languages, Lanzhou Univ. of Tech., Lanzhou, 730050, China \\ jiaxf3366@163.com
}

\begin{abstract}
Globalization is creating a rapidly increasing demand for engineers in our society who have a solid understanding of both expertise and culture. Understanding culture, cultivating cultural awareness and cultural creativity and recognizing the need to effectively apply these needs to practice are becoming critical success factors for an increasing number of engineers. To elaborate this point, what cultural engineers are and how to cultivate cultural engineers are respectively discussed.
\end{abstract}

Index Terms - cultural engineers, cultural awareness, cultural creativity

\section{Introduction}

For the word "engineer", its root is "engine" which literally means the machine that converts energy into power or motion and figuratively means a driving force that push the society forward. No matter how to understand, we can conclude that "engineer" plays an indispensable role in social development. However, we are entering an age when the culture and cultural creativity are becoming all the more important assets. Therefore, the Higher Education should undertake the responsibility of cultivating engineers who must be armed with both expertise and culture.

\section{The Definition of Cultural Engineers}

As a newly-coined phrase, there are different understandings of "Cultural Engineer", and generally speaking, Cultural Engineer refers to the people who is mainly responsible for establishing the enterprise culture and play multiple roles in helping company always full of vitality, personality and humanity. Yet a few other people think Cultural Engineer should not only have a solid understanding of technology but be capable of smoothing over any small misunderstandings arising mainly in joint ventures before they escalate into big emotional conflicts, that is, they have a deep insight into cross-cultural communication skills. As far as I am concerned, more specifically, firstly, Cultural Engineer should be loyal and conscientious. They are supposed to be loyal to their company and country, and likewise a strong sense of responsibility for society is highly valued. Pursuing perfect technology and high-quality products will undoubtedly become their faith. Secondly, Cultural Engineer should be ambitious and virtuous. Having a clear life goal is the premise of self-cultivation. An ambitious engineer tends to create much more wealth for the society. Moreover, Cultural Engineer ought to be clear about such philosophy as "Don't expect others to do what you don't want to do yourself", "Honesty is best polity", "Cooperation is power", "Genius is $99 \%$ perspiration and $1 \%$ inspiration" etc. Thirdly, Cultural Engineer should be optimistic and knowledgeable. An optimistic man is often beneficial to create a pleasant and positive working environment and in which the cooperation can go smoothly, effectively and productively. Actually having a good command of expertise and variously relevant knowledge is the very basic quality for Cultural Engineer to achieve success. Finally, Cultural Engineer should be creative and innovative. Since we have been in an age when the development of economy rest so much on the engineer' creativity and innovation, Cultural Engineer's creativity should be highly valued. In a word, Cultural Engineer had better be compound talents with perfect skills and great cultural awareness and cultural creativity, and they all along consider "boosting national economy and benefitting mankind" as their mission and all along adhere to "self- discipline and great virtue".

\section{The Background of Cultivating Cultural Engineers}

Today, it is well-known throughout the whole world that human beings have entered the age of globalization. In this age, Great changes have taken place in almost every field, and there is in fact an ongoing trend of culturalization of technology, a prime example of which is the recent development in the design of products. The value-added of various products is increasingly based on the cultural value rather than its utility value. For many people, their decisions to buy a product depend primarily on other considerations than that they can use the device. As an active participant in globalization, if China wants to take the initiative in global competition, it should try to adapt to this ever-changing and culture-oriented world. Likewise, as the direct creator of social wealth, engineers should recognize the intrinsic value of culture and realize that the competition among similar products will largely and increasingly rely on their creativity and virtues and that the creativity and virtues does not come from anywhere but culture. Therefore, Cultural Engineers who have both professional and cultural competence to effectively and flexibly cope with any technological and social problems are urgently and considerably demanded by globalized China.

On the other hand, throughout Chinese history, during long feudal society, Chinese society always placed emphasis on humanity rather than science, which led to the prosperity of human science. However since modern and contemporary times, due to the change of conceptions, science began to be blindly and reversely valued, and "science saving country" is 
simply considered as "science and technology saving country", in this case, to some degree humanity was impulsively discarded, while science is greatly favored. Most educated people especially engineers paid more attention on expertise than culture. The cultural awareness and cultural creativity were ignored, and plus the loss of human spirit and the decline of moral values caused by globalization, Chinese modern engineers are gradually losing their competitiveness in global economy, which caused that "made in China" is often misunderstood and even discriminated in international market. In the face of such situation, in order to revitalize and popularize "made in China", there is an urgent need for Cultural Engineers.

\section{How to Cultivate Cultural Engineers}

Educating the modern engineers to be more culturally savvy has become a consensus of the whole society. For modern engineers, their success in globalizing economy is based above all on the ability to utilize expertise in the culturally creative way, which means engineers should always keep such things in mind as social responsibility, concern for the environment, self-improvement and so on when they are engaged in their jobs. In this part, how to cultivate Cultural Engineers will be discussed from three aspects, namely, to help engineering students expand their scope of knowledge; to cultivate engineering students' cultural awareness; to cultivate engineering students' cultural creativity.

\section{A. To help engineering students expand their scope of knowledge}

The more and more elaborate social division of labor caused by Industrial Revolution come to result in the lack of understandings and communications among different trades and among different disciplines, which to some extent restrict engineering students' horizon and creativity. Besides, in this economy-oriented society, the Chinese engineering students spend less and less time on reading and improving their cultural cultivation, and thus their scope of knowledge is seriously narrowed; their cultural cultivation was neglected and their imagination was almost stifled, which lead to a result that Chinese engineering graduates are short of cultural awareness and cultural creativity.

For the above reasons, to greatly widen engineering students' scope of knowledge, China's Higher Education especially Universities of Science and Technology should firstly strive to innovate its educational conception and reform its educational system, and then under the guidance of the conceptions of Quality Education and General Education, they must try to create a rich campus human and academic environment in which students will consciously and unconsciously be influenced. In addition, in class teachers had better adopt effective methods to make their lectures full of a strong flavor of humanities and try to guide and encourage students to do more reading after class. For instance, in class, engineering teachers could be used to combine the western theory with Chinese examples like the Four Great Inventions so as to cultivate students' thinking habits and help students form an idea that great inventions tend to come from cultural creativity rather than pure skills and technology. All in all, engineering students' professional future is majorly based on whether they have widened their scope of knowledge in university. As a Chinese famous scholar named Ji Xianlin said: "Almost nobody objects to the requirement for a wide scope of knowledge, because no matter how narrow and specialized your research is, as long as you acquire a wide scope of knowledge, you will be far-sighted and your research will be promising." Therefore, expanding engineering students' scope of knowledge should be given priority to in the cultivation of successful Cultural Engineers.

\section{B. To cultivate engineering students' cultural awareness}

Acquiring a wide scope of knowledge is not equal to possessing a high cultural awareness, because cultural awareness is in some sense acquired through thinking, understanding, insight, and even perception instead of reading and accumulation.

In modern Chinese society, the educational system is mainly exam-oriented and thus the current teaching method still stay with the traditional cramming method of teaching, which doesn't help engineering students digest what they have been taught and doesn't help them cultivate the ability of thinking independently and even their cultural awareness. In order to cultivate engineering students' cultural awareness, it is crucial to change the conventional education patterns and focus more on students' abilities to think independently and creatively and on students' virtues to behave honestly and elegantly. And thus teachers should firstly encourage engineering students to study not only natural science but also human and social science and then help them achieve mastery through a comprehensive study. Next teachers need to guide students to acquire virtues like honesty, diligence, optimism, self-confidence. co-operation, sense of competition, sense of responsibility etc. and more importantly try to combine their expertise with these virtues. Finally students should be helped to establish correct world outlook and views on life and values and strive to become the compound Cultural Engineers with knowledge, virtues, ideal and taste.

\section{To cultivate engineering students' cultural creativity}

As we all know, engineers' responsibility is to create direct wealth for society, and obviously the purpose of cultivating Cultural Engineers is to help engineers make more creative and valuable contributions to society. For this, a Cultural Engineer's value should be judged by his creation, that is, his contributions to society rather than whether his has cultural awareness or not. Therefore, based on cultural awareness, cultivating engineering students' cultural creativity should be the key task.

What is cultural creativity? From the economic perspective, cultural creativity is tantamount to the ability to develop internationally successful products based on the utilization of cultural capital. On the corporate level, cultural creativity is based on a broad combination of skill and 
expertise where things related to cultural development are read correctly and used in the right way. For instance, a product's design is often regarded as a discipline that is only connected to aesthetics. However, in fact, it is a much broader field, involving not only the external appearance of a product, but its quality, attractiveness and thereby its competitiveness.

Today, we are entering an economy where the main driving force is cultural creativity and ever more tasks in the private as well as public sectors call for more than just repetition of old patterns, in other words, the creation of new things. For this we need to cultivate engineering students with new skills, particularly those that can be labeled as cultural creativity. However, for a long time, since Chinese educational system is exam-oriented, the engineering students had to be committed to improving their memory and testing skills, and thus their creativity was seriously hurt. Yet in fact, the cultivation of cultural creativity is closely related to imagination and hands-on capability. Therefore, to cultivate engineering students' cultural creativity, based on expanding their scope of knowledge and cultivating their cultural awareness, teachers should spare no efforts to create opportunities to stimulate students' imagination and hands-on capability, for instance, teachers could choose to give lectures in labs or internship workshop instead of traditional classroom; teachers could adopt case study rather than textbook study etc. In addition, universities should try to create an excellent academic and human environment in order to help students avoid being infected with pragmatism and utilitarianism, because keeping a peaceful and pure heart is critical for engineering students to cultivate cultural creativity.

\section{Conclusion}

Culture and cultural creativity are becoming all the more important assets for society. In western countries, culture and economy are understood two separate things. The concept of culture is associated with something sublime and distant, while economy is seen mostly in terms of moneymaking. Comparatively in China, though for a long time, culture seemed to be treated with indifference, but in recent years, culture has resumed being valued by whole society, and there is an obvious tendency that culture is becoming another important driving force for economy, for example the rapid rise of cultural industry, the fast establishment of Confucius Institute, the increasing concern for Chinese traditional festivals etc. Economy and culture has actually become closely-related and supplementary, and for this whether Chinese engineers are able to take advantage of the abundant cultural resources to promote economic development has become a social issue. In fact, Engineers will not be capable of making best use of the abundant cultural resources unless they themselves are equipped with great cultural awareness and cultural creativity. The future will be bound to show that a competitive and prosperous society will rest more on the creativity and innovation of an increasing number of Cultural Engineers.

\section{References}

[1] Markuu Wilenius, J. (2006), "Cultural Competence in the Business World: a Finnish Perspective": Journal of Business Strategy, Vol. 27 No. 4, pp. 43-49

[2] Castells, M. (2000), "The Information Age: Economy, Society and Culture", The Rise of the Network Society, 2nd ed., Vol. 1, Blackwell Publishers, London.

[3] Halvard E. Nystrom Ph.D, "Managing Cultural Differences for Engineers": 1997, Frontiers in Education Conference, p. 812. 